\title{
STUDY OF CLINICO-PATHOLOGICAL PROFILE, RADIOLOGICAL PATTERN OF NEW SMEAR POSITIVE (CATEGORY I) PULMONARY TUBERCULOSIS RIFAMPICIN-RESISTANT PATIENTS IN SRMSIMS
}

\author{
Rajeev Tandon'1, Sumit Prakash², Anurag Agrawal ${ }^{3}$, Lalit Singh ${ }^{4}$
}

${ }_{1}^{1}$ Assistant Professor, Department of Respiratory Medicine, Sri Ram Murti Smarak Institute of Medical Sciences, Bareilly, Uttar Pradesh. ${ }^{2}$ Postgraduate Student, Department of Respiratory Medicine, Sri Ram Murti Smarak Institute of Medical Sciences, Bareilly, Uttar Pradesh.

3Professor, Department of Respiratory Medicine, Sri Ram Murti Smarak Institute of Medical Sciences, Bareilly, Uttar Pradesh. ${ }^{4}$ Professor, Department of Respiratory Medicine, Sri Ram Murti Smarak Institute of Medical Sciences, Bareilly, Uttar Pradesh.

\section{ABSTRACT}

\section{BACKGROUND}

Tuberculosis (TB) is a curable and preventable disease, which is caused by Mycobacterium TB (MTB). It most commonly affects the lungs, but can potentially involve any system or organ of the body. It is estimated that one untreated infectious TB patient is likely to infect 10 - 15 people, because when they cough or sneeze they expel large number of droplets containing large number of bacteria. Sputum smear positive (SSP) pulmonary TB patients are the most significant source of droplet nuclei, which carry infectious bacilli. The situation is made worse by the emergence of drug-resistant TB, particularly the multi-drug resistant (MDR) and extensively drug-resistant (XDR) TB. A case of MDR-TB is about 20 - 40 times more expensive to manage than a case of drugsensitive.

Aims and Objectives- To study the profile of patient's symptoms, signs and radiological abnormalities in new smear positive pulmonary tuberculosis Rifampicin-resistant patients.

\section{MATERIALS AND METHODS}

60 patients who were new smear positive, admitted during 6 months period were seen for Rifampicin resistance and studied for clinico-pathological profile and radiological pattern.

\section{RESULTS}

60 patients were studied, out of those 60 patients, 5 patients were documented with Rifampicin resistance, and all of them belonged to $2 \mathrm{nd}$, 3rd and 4th decade, i.e. younger age group and $80 \%$ were males and $20 \%$ were females with male-to-female ratio of 4:1 respectively. Cough (100\%), breathlessness (100\%), fever $(80 \%)$ and weight loss $(80 \%)$ were the most common presenting clinical features. The chest $\mathrm{x}$-ray of rifampicin resistance patients showed that $81.7 \%$ had unilateral and $18.3 \%$ had bilateral disease. Out of those, $40 \%$ had destroyed lung, $40 \%$ had cavitatory lesions and $20 \%$ had bronchiectasis with infiltration on chest $\mathrm{x}$ ray (PA view).

\section{CONCLUSION}

One of the concerning issues was that there were no definitive clinical or routine investigations connected with rifampicin resistance, thus showing that passage of resistant strain is quite prevalent in society. To tackle this problem, it is recommended that drug resistance evaluation should be made mandatory part of the tuberculosis control programme and appropriate customised management strategies in view of the drug resistance pattern of individual patient should be made.

\section{KEYWORDS}

Tuberculosis, Sputum Smear Positive, Multidrug Resistance TB, GeneXpert, Drug Susceptibility Test.

HOW TO CITE THIS ARTICLE: Tandon R, Prakash S, Agrawal A, et al. Study of clinico-pathological profile, radiological pattern of new smear positive (category I) pulmonary tuberculosis rifampicin-resistant patients in SRMSIMS. J. Evolution Med. Dent. Sci. 2018;7(15):1912-1918, DOI: 10.14260/jemds/2018/430

\section{BACKGROUND}

Tuberculosis (TB) is a curable and preventable disease, which is caused by Mycobacterium TB (MTB). It most commonly affects the lungs, but can potentially involve any system or organ of the body. It is estimated that one untreated infectious TB patient is likely to infect 10 - 15 people, because

'Financial or Other Competing Interest': None.

Submission 16-02-2018, Peer Review 25-03-2018,

Acceptance 31-03-2018, Published 09-04-2018.

Corresponding Author:

Dr. Rajeev Tandon,

Department of Respiratory Medicine,

OPD No. 8, SRMSIMS, Bhojipura,

Bareilly-243202, Uttar Pradesh.

E-mail: montoo1969@gmail.com

DOI: $10.14260 /$ jemds $/ 2018 / 430$

(c) (i) $(9)$ when they cough or sneeze they expel large number of droplets containing large number of bacteria. Sputum smear positive (SSP) pulmonary TB patients are the most significant source of droplet nuclei, which carry infectious bacilli. The situation is made worse by the emergence of drug-resistant $\mathrm{TB}$, particularly the multidrug resistant (MDR) and extensively drug-resistant (XDR) TB. A case of MDR-TB is about 20 - 40 times more expensive to manage than a case of drug-sensitive.

The aim of current study was to determine the clinical characteristics, radiological pattern in new smear-positive pulmonary tuberculosis cases in a tertiary care hospital.

\section{Aims and Objectives}

To study the profile of patient's symptoms, signs and radiological abnormalities in new smear positive pulmonary tuberculosis Rifampicin-resistant patients. 


\section{Study Design}

Prospective observational study.

\section{Study Period}

January 2016 to June 2016. In this timeframe, all newly sputum positive patients are taken for study after applying inclusion and exclusion criteria.

\section{MATERIALS AND METHODS}

60 patients who were new smear positive, admitted during 6 months period were seen for Rifampicin resistance and studied for clinico-pathological profile, radiological pattern. All the patients falling in sampling frame were invited to participate in the study. Only those providing consent were enrolled in the study. After enrolment in the study, the patients were selected irrespective of age or sex with symptoms such as cough, low-grade fever, haemoptysis, chest pain, weight loss, loss of appetite or anorexia. A detailed history of previous anti-tubercular treatment was taken and only those patients who had never had treatment for tuberculosis (new case or category I) were included. Ethics permission was taken. A detailed history was taken with particular reference to demographic information, socioeconomic status and family history of tuberculosis. A thorough general physical and systemic examination was carried out. All cases were subjected to haemogram, hepatic and renal function tests, blood sugar and chest $\mathrm{x}$-ray (PA view).

All patients were directed to collect the early morning sputum specimen in a sterilised wide-mouthed bottle with a tightly-fitting cork stopper. Sputum was sent for smear for Acid-Fast Bacilli (AFB) on three consecutive days. All sputum samples were transported to the microbiology lab as soon as possible after collection. The smears were screened for AcidFast Bacilli (AFB) and positive smears were graded as per Revised National Tuberculosis Control Programme (RNTCP) guidelines.

Drug resistance pattern was studied using GENEXPERT test.

\section{GeneXpert MTB/ RIF Assay Procedure}

GeneXpert MTB/ RIF assay is a nucleic acid amplification (NAA) test, which simultaneously detects DNA of Mycobacterium tuberculosis complex (MTBC) and resistance to rifampin (RIF) (i.e. mutation of the rpoB gene) in less than 2 hours. In comparison, standard cultures can take 2 to 6 weeks for MTBC to grow and conventional drug resistance tests can add 3 more weeks.

\section{Inclusion Criteria}

- Newly diagnosed sputum positive cases of pulmonary tuberculosis.

- Newly diagnosed patients of pulmonary tuberculosis with ATT history for less than 1 month.

- Patient diagnosed as primary resistant tuberculosis from outside.

\section{Statistical Methods}

The statistical analysis was done using SPSS (Statistical Package for Social Sciences) Version 20.0 Statistical Analysis Software. The values were represented in Number (\%). The following statistical test was used:
1. Chi-square Test

$$
\chi^{2}=\sum \frac{(O-E)^{2}}{E}
$$

Where $\mathrm{O}=$ Observed frequency.

$\mathrm{E}=$ Expected frequency.

2. Level of Significance: " $p$ " is level of significance.

$p>0.05$ Not significant.

$\mathrm{p}<0.05$ Significant.

$\mathrm{p}<0.01$ Highly significant.

$\mathrm{p}<0.001$ Very highly significant.

\section{RESULTS}

60 patients were studied, out of those 5 patients were documented with Rifampicin resistance and all of those belonged to $2 \mathrm{nd}$, 3rd and 4 th decade, i.e. younger age group and $80 \%$ were males and $20 \%$ were females with male-tofemale ratio of 4: 1 respectively. Cough (100\%), breathlessness (100\%), fever (80\%) and weight loss (80\%) were the most common presenting clinical features. The chest $\mathrm{x}$-ray of rifampicin resistance patients showed that $81.7 \%$ had unilateral and $18.3 \%$ had bilateral disease. Out of those $40 \%$ had destroyed lung, $40 \%$ had cavitatory lesions and $20 \%$ had bronchiectasis with infiltration on chest x-ray (PA view).

\section{Rifampicin Resistance and Sensitive Ratio}

\begin{tabular}{|c|c|c|c|c|c|c|c|}
\hline \multicolumn{8}{|c|}{$\begin{array}{c}\text { Table 2: Association of demographic variables with RIFAMPICIN } \\
\text { RESISTANT Status }\end{array}$} \\
\hline \multirow[t]{2}{*}{ SN } & \multirow[t]{2}{*}{ Characteristic } & \multicolumn{2}{|c|}{ Total $(n=60)$} & \multicolumn{2}{|c|}{$\begin{array}{l}\text { Sensitive } \\
(\mathrm{n}=55)\end{array}$} & \multicolumn{2}{|c|}{$\begin{array}{l}\text { Resistant } \\
(n=5)\end{array}$} \\
\hline & & No. & $\%$ & No. & $\%$ & No. & $\%$ \\
\hline \multirow{5}{*}{1} & Age & & & & & & \\
\hline & $20-40$ Yrs & 14 & 23.3 & 9 & 16.4 & 5 & 100.0 \\
\hline & $40-65$ Yrs & 26 & 43.3 & 26 & 47.3 & 0 & 0.0 \\
\hline & $>65$ Yrs & 20 & 33.3 & 20 & 36.4 & 0 & 0.0 \\
\hline & & & & \multicolumn{4}{|c|}{$\chi^{2}=17.922(\mathrm{df}=2) ; p<0.001$} \\
\hline \multirow{5}{*}{2} & Gender & & & & & & \\
\hline & Male & 45 & 75.0 & 41 & 74.5 & 4 & 80.0 \\
\hline & Female & 15 & 25.0 & 14 & 25.5 & 1 & 20.0 \\
\hline & Male: Female & \multicolumn{2}{|c|}{$3: 1$} & & $2.93: 1$ & \multicolumn{2}{|c|}{$4: 1$} \\
\hline & & & & \multicolumn{4}{|c|}{$\chi^{2}=0.073(d f=1) ; p=0.787$} \\
\hline
\end{tabular}
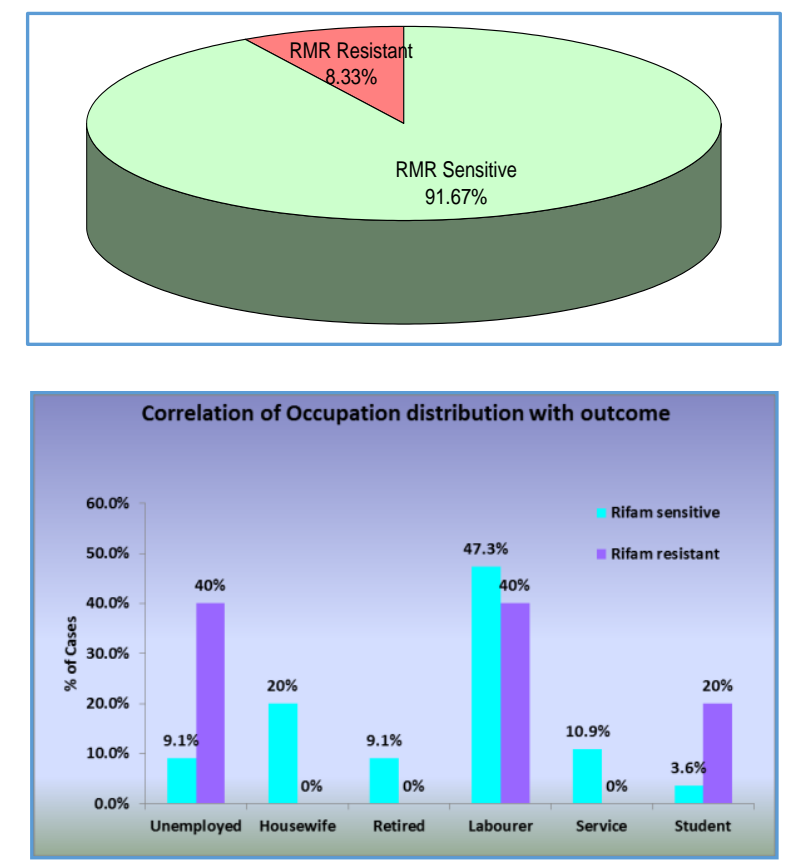

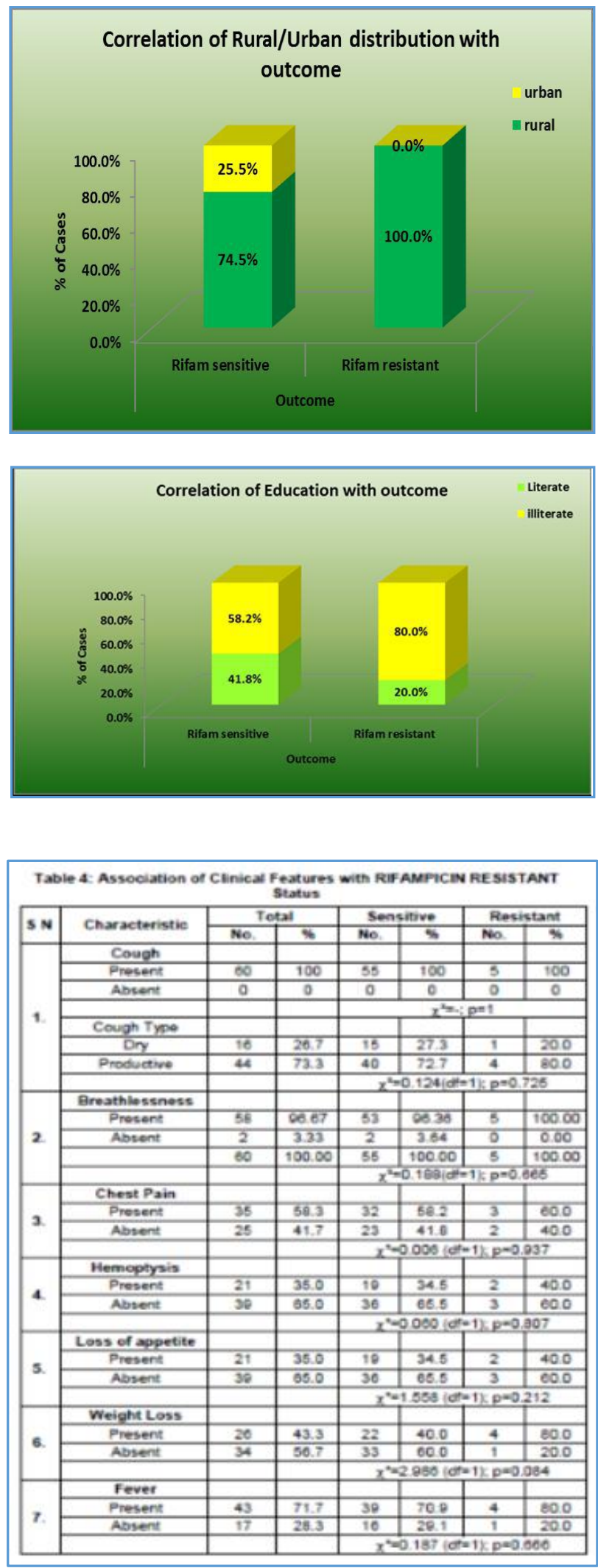

Table 5: Association of Medical and Family History with RIFAMPICIN

\begin{tabular}{|c|c|c|c|c|c|c|c|}
\hline \multirow[t]{2}{*}{ SN } & \multirow[t]{2}{*}{ Characteristic } & \multicolumn{2}{|c|}{ Total $(n=60)$} & \multicolumn{2}{|c|}{$\begin{array}{l}\text { Sensitive } \\
(n=55)\end{array}$} & \multicolumn{2}{|c|}{$\begin{array}{l}\text { Resistant } \\
(\mathrm{n}=5)\end{array}$} \\
\hline & & No. & $\%$ & No. & $\%$ & No. & $\%$ \\
\hline \multirow{4}{*}{1.} & \multicolumn{7}{|c|}{ Diabetes Mellitus } \\
\hline & Present & 5 & 8.3 & 4 & 7.3 & 1 & 20.0 \\
\hline & Absent & 55 & 91.7 & 51 & 92.7 & 4 & 80.0 \\
\hline & & & & \multicolumn{4}{|c|}{$\chi^{2}=0.972(d f=1) ; p=0.324$} \\
\hline \multirow{4}{*}{2.} & \multicolumn{7}{|c|}{ Family history of TB } \\
\hline & Present & 10 & 16.7 & 8 & 14.5 & 2 & 40.0 \\
\hline & Absent & 50 & 83.3 & 47 & 85.5 & 3 & 60.0 \\
\hline & & & & \multicolumn{4}{|c|}{$\chi^{2}=2.138(d f=1) ; p=0.148$} \\
\hline
\end{tabular}

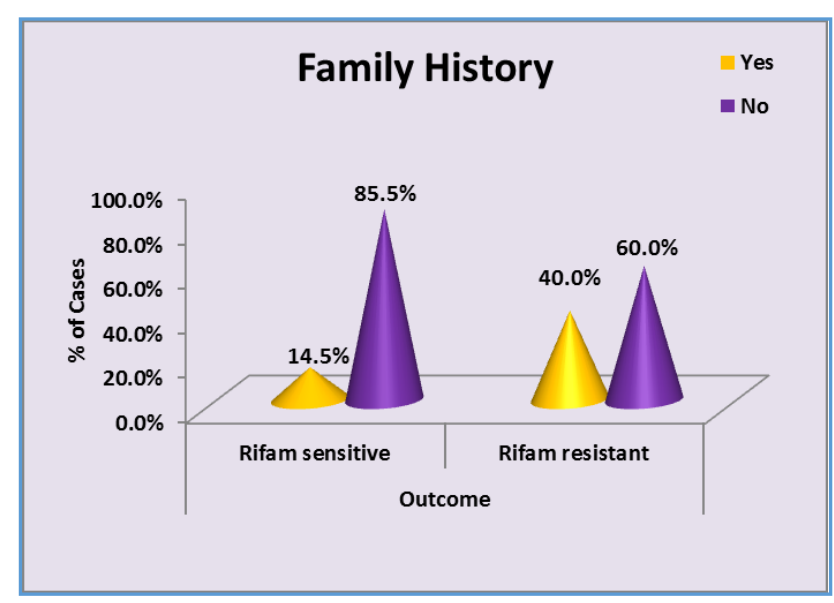

Table 7: Clinical Examination

\begin{tabular}{|l|l|l|l|l|l|l|l|l|l|}
\hline \multirow{2}{*}{ SN } & Characteristic & \multicolumn{2}{|l|}{$\begin{array}{l}\text { Total } \\
(\mathrm{n}=60)\end{array}$} & \multicolumn{3}{l|}{$\begin{array}{l}\text { Sensitive } \\
(\mathrm{n}=55)\end{array}$} & \multicolumn{2}{l|}{$\begin{array}{l}\text { Resistant } \\
(\mathrm{n}=5)\end{array}$} & \multicolumn{3}{|l}{$\begin{array}{l}\text { Statistical } \\
\text { significance }\end{array}$} \\
\cline { 3 - 11 } & & No. & $\%$ & No. & $\%$ & No. & $\%$ & $\chi^{2}$ & \\
\hline 1- & Pallor & 15 & 25.0 & 14 & 25.5 & 1 & 20.0 & 0.073 & 0.787 \\
\hline 2- & Icterus & 4 & 6.7 & 4 & 7.3 & 0 & 0.0 & 0.390 & 0.533 \\
\hline 3- & $\begin{array}{l}\text { Lymphadeno- } \\
\text { pathy }\end{array}$ & 0 & 0.00 & 0 & 0.00 & 0 & 0.00 & - & - \\
\hline 4- & Clubbing & 2 & 3.3 & 2 & 3.6 & 0 & 0.0 & 0.188 & 0.665 \\
\hline 5. & Oedema & 2 & 3.3 & 2 & 3.6 & 0 & 0 & 0.188 & 0.665 \\
\hline 6. & Cyanosis & 0 & 0 & 0 & 0 & 0 & 0 & - & - \\
\hline
\end{tabular}

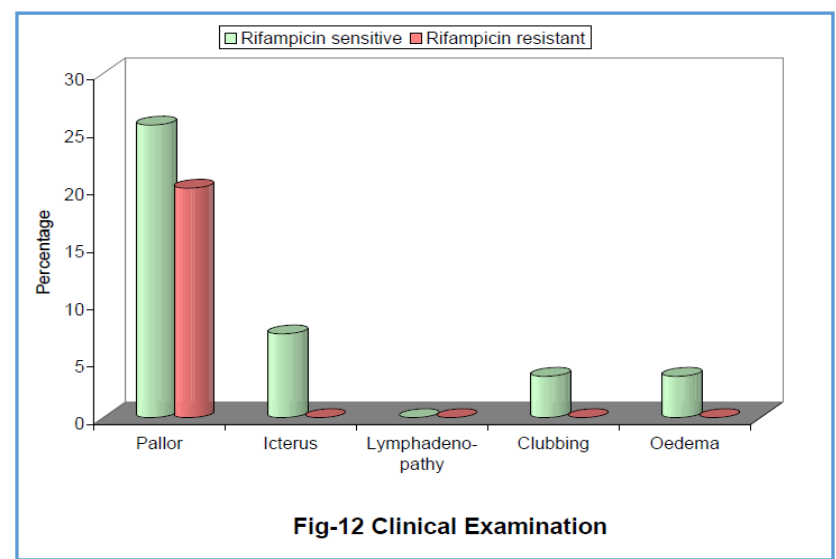




\begin{tabular}{|c|c|c|c|c|c|c|c|}
\hline \multicolumn{8}{|c|}{$\begin{array}{l}\text { Table 9: Association of location of Chest X-Ray lesion with } \\
\text { RIFAMPICIN RESISTANT Status }\end{array}$} \\
\hline \multirow[t]{3}{*}{ CXRPA } & \multicolumn{6}{|l|}{ Outcome } & \multirow{3}{*}{$\begin{array}{l}\mathrm{P} \\
\text { Value }\end{array}$} \\
\hline & \multicolumn{2}{|l|}{$\begin{array}{l}\text { Rifampicin } \\
\text { sensitive }\end{array}$} & \multicolumn{2}{|l|}{$\begin{array}{l}\text { Rifampicin } \\
\text { resistant }\end{array}$} & \multicolumn{2}{|l|}{ Total } & \\
\hline & $\begin{array}{l}\text { Frequenc } \\
y\end{array}$ & $\%$ & $\begin{array}{l}\text { Frequenc } \\
\mathrm{y}\end{array}$ & $\%$ & $\begin{array}{l}\text { Frequenc } \\
y\end{array}$ & $\%$ & \\
\hline $\begin{array}{l}\text { Unilater } \\
\text { al }\end{array}$ & 46 & $\begin{array}{l}83.6 \\
\%\end{array}$ & 3 & $\begin{array}{l}60.0 \\
\% \\
\end{array}$ & 49 & $\begin{array}{l}81.7 \\
\%\end{array}$ & \multirow[t]{3}{*}{0.224} \\
\hline Bilateral & 9 & $\begin{array}{l}16.4 \\
\%\end{array}$ & 2 & $\begin{array}{l}40.0 \\
\%\end{array}$ & 11 & $\begin{array}{l}18.3 \\
\%\end{array}$ & \\
\hline Total & 55 & $100 \%$ & 5 & $100 \%$ & 60 & $100 \%$ & \\
\hline
\end{tabular}

\begin{tabular}{|c|c|c|c|c|c|c|c|}
\hline \multicolumn{8}{|c|}{$\begin{array}{l}\text { Table 10: Association of Type of Chest X-Ray lesion with RIFAMPICIN } \\
\text { RESISTANT Status }\end{array}$} \\
\hline \multirow{3}{*}{$\begin{array}{l}\text { Chest } X \text { ray } \\
\text { type lesion }\end{array}$} & \multicolumn{6}{|c|}{ Outcome } & \multirow{3}{*}{$\begin{array}{c}P \\
\text { Value }\end{array}$} \\
\hline & \multicolumn{2}{|c|}{$\begin{array}{c}\text { Rifampicin } \\
\text { sensitive }(n=55)\end{array}$} & \multicolumn{2}{|c|}{\begin{tabular}{|c|}
$\begin{array}{c}\text { Rifampicin } \\
\text { resistant }(n=5)\end{array}$ \\
\end{tabular}} & \multicolumn{2}{|c|}{ Total $(n=60)$} & \\
\hline & Frequency & $\%$ & Frequency & $\%$ & Frequency & $\%$ & \\
\hline infiltration & 23 & $41.8 \%$ & 0 & $0.0 \%$ & 23 & $38.3 \%$ & 0.146 \\
\hline $\begin{array}{l}\text { brochiactesis } \\
\text { with infiltration }\end{array}$ & 3 & $5.5 \%$ & 1 & $20.0 \%$ & 4 & $6.7 \%$ & 0.301 \\
\hline cavity & 7 & $12.7 \%$ & 2 & $40.0 \%$ & 9 & $15.0 \%$ & 0.158 \\
\hline destroyed lung & 5 & $9.1 \%$ & 2 & $40.0 \%$ & 7 & $11.7 \%$ & 0.099 \\
\hline $\begin{array}{c}\text { fibrosist } \\
\text { infiltration }\end{array}$ & 0 & $0.0 \%$ & 0 & $0.0 \%$ & 0 & $0.0 \%$ & - \\
\hline consolidation & 19 & $34.5 \%$ & 0 & $0.0 \%$ & 19 & $31.7 \%$ & 0.168 \\
\hline
\end{tabular}
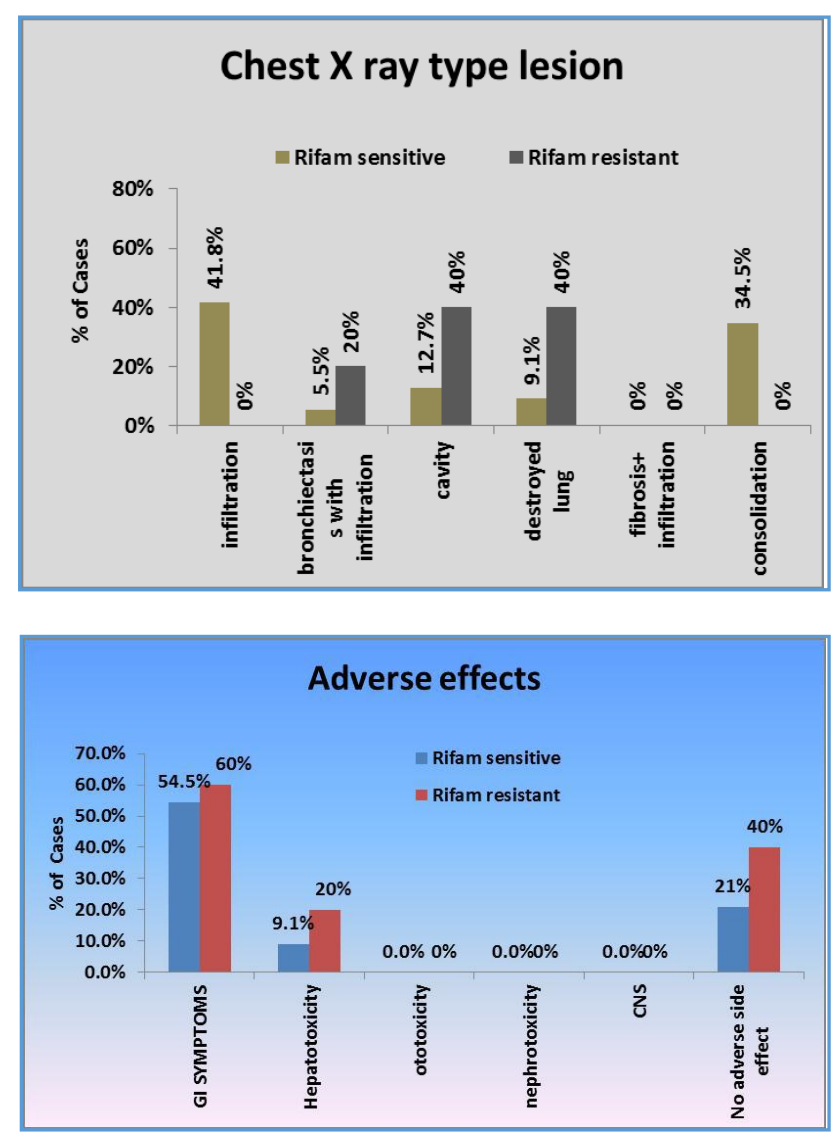

\section{DISCUSSION}

Drug resistance is emerging as one of the major obstacles in tackling with global epidemic of tuberculosis. Since the introduction of modern tuberculosis chemotherapy, there has been a steady increase in the emergence of drug resistance. ${ }^{1}$
Various biological factors contribute to the development of drug resistance, but the most important ones are poor compliance, improper dosing and inadequate duration of chemotherapy. ${ }^{2,3}$ As resistant organisms retain their virulence and infectivity, the resistant strains have been gradually increasing in the community. ${ }^{4}$ Management of drug-resistant tuberculosis is more difficult, complicated, challenging and costlier. 5

Although, drug-resistant tuberculosis is observed in previously treated patients because of past incorrect or irregular treatment, it is also observed in new, previously untreated patients because of transmission of drug-resistant strains. ${ }^{6}$ The treatment of drug-resistant tuberculosis often requires second-line drugs and should be guided by drug susceptibility test (DST) results. ${ }^{7}$ Unfortunately, in many countries that have high burdens of drug-resistant tuberculosis, new patients with drug-resistant and even multidrug-resistant tuberculosis (MDR-TB) are often treated empirically with first-line drugs. The reasons for this include a lack of access to second-line drugs, a lack of laboratory facilities capable of performing DSTs, and a lengthy turnaround time for DST results for many commonly used techniques.8,9

Drug resistance could be categorised as monoresistant, polyresistant or multidrug resistant, depending on the number and types of drugs against which resistance is found. Among monoresistant cases, rifampicin resistance has been reported quite widely. ${ }^{10}$ One of the most common reasons for drug resistance is discontinuation of treatment in between. ${ }^{11}$ However, it is of concern that newly diagnosed cases of tuberculosis also show a high incidence of rifampicin resistance, thus making it imperative to study the problem and to formulate appropriate strategies to tackle this problem. ${ }^{12}$

With this background, the present study was planned with an aim to assess rifampicin resistance among newly diagnosed sputum positive cases of pulmonary tuberculosis. For this purpose, a total of 60 newly diagnosed sputum positive cases of pulmonary tuberculosis were enrolled and subjected to rifampicin resistance evaluation using GenExpert diagnostic kit. It must be understood that resistance to rifampin arises due to mutations in the beta subunit of RNA polymerase encoded by the gene rpoB. 13 Almost, all of the corresponding mutations in rpoB occur in a small region of less than 100 bp with less than $5 \%$ occurring outside of this region. ${ }^{14}$ This includes point mutations, deletions and insertions. GeneXpert is an automated realtime polymerase chain-reaction assay designed for the rapid and simultaneous detection of MTB and rifampicin resistance. ${ }^{15}$ The assay amplifies a MTB-complex-specific region of the RPOB gene, which is probed with molecular bonfires to detect the presence of rifampicin resistancedetermining mutations. ${ }^{16}$

Rifampicin resistance rates in different studies to be ranging from $0.8 \%$ to $9.9 \% .17$ There were distinct regional differences in prevalence of rifampicin resistance. Among studies from Ethiopia these rates ranged from $2.2 \%$ to $3.89 \% .^{18}$ However, studies from Nigeria and South Africa reported these rates to range from $7.1 \%$ to $8.8 \%$. The single study from Kenya reported it as $1.7 \% .{ }^{19}$ Two studies from Iran reported rifampicin rates as $7.4 \%$ and $11.8 \%$ respectively. ${ }^{20}$ Among studies from India, Moitra et al 
(2014) ${ }^{21}$ Delhi reported prevalence of rifampicin resistance alone or in poly/ MDR cases was $15.8 \%$ which was higher than the present study. Das et al (2016) ${ }^{9}$ reported rifampicin resistance in $2.27 \%$ cases only; however, Agwan et al (2015) 22 reported rifampicin mono-resistance in $4.5 \%$ and as MDR-TB in $7.2 \%$ cases. Kaur et al $(2016)^{7}$ has rifampicin resistance rates of $9.9 \%$, which is quite close to the Rifampicin resistance rates in the present study (8.33\%). The reasons for these differences could be multiple like difference in profile of patients, inclusion of mixed cases (newly diagnosed as well as previously treated cases), difference in methods of estimation, difference in inclusion criteria (Sputum positive versus culture positive) and a host of other locoregional differences.

The present study found a significant association between younger age (20 - 40 years) with rifampicin resistance. Similar association of younger age with rifampicin resistance was observed by Coovadia et al (2013). ${ }^{23}$ In his study which included 16,748 patients for susceptibility to RIF and INH over a three-year period and found that in comparison to the 50 plus age group, rifampicin resistance was $37 \%$ more likely to occur in the 25 - 29 years age category. In another study, Adane et al (2015) ${ }^{2}$ also found that age group of 25 - 34 years was at higher odds $(\mathrm{OR}=4.24)$ and previous history of treatment were independently associated with anti-TB drug resistance. Moitra et al (2014) ${ }^{21}$ found that majority of patients belonged to $2 \mathrm{nd}$, 3rd and 4 th decade like in the present study.

One of the possible reasons for this could be the fact that this age group represents the most active life-stage of human beings during which an individual comes in contact with a variety of persons from different background and unlike childhood and elderly age group in this age group the protective environment is not as secure thus leading to increased susceptibility to opportunistic infections through contact. In another study among suspected cases of MDR-TB, Guled et al $(2016)^{8}$ have also reported dominance of productive age group (21 - 40 years) $(68.62 \%)$. Mukherjee et al $(2015)^{3}$ in their study on MDR/ XDR-TB patients in Kolkata also found younger age (21 - 30 years) to be the most common, thus indicating that younger age has to do something with increased risk of drug resistance even in newly diagnosed tuberculosis cases.

In present study, overall $75 \%$ were male and $25 \%$ were female with proportion of males higher in resistant group as compared to sensitive, but no significant association between gender and rifampicin resistance was observed. However, Coovadia et al (2013) ${ }^{23}$ in their study from South Africa reported higher odds of rifampicin resistance among males as compared to females. Similarly, Mulu et al $(2017)^{24}$ also reported higher odds of rifampicin resistance among males as compared to females. In another study, Rasaki et al (2014) 25 found equal risk of rifampicin resistance among males and females. Thus, gender-associated risk can be set aside as incidental, only more so keeping in view the small sample size of present study.

The present study predominantly had patients from rural areas $(76.7 \%)$ and illiterates (60\%). Maximum (46.7\%) were labourers. Tuberculosis patients generally come from underprivileged sections of society often living in conditions where susceptibility to infection is quite frequent. The economic divide in incidence of drug resistance is quite evident with a higher prevalence of drug resistance in underdeveloped countries as compared to developed countries.

In present study, cough was reported by all the newly diagnosed smear positive cases. Among other common clinical features were productive cough (73.3\%), breathlessness $(96.7 \%)$, chest pain $(58.3 \%)$ and fever (71.7\%). The clinical profile of our patients was similar to that reported by Moitra et al (2014),21 who in a study of 100 cases of new smear positive pulmonary tuberculosis cases found cough (83\%), fever (77\%) and weight loss (76\%) as the most common presenting clinical features and did not specify any clinical or radiological correlation with the drug resistance. In present study, we also did not find any significant association of these clinical features with rifampicin resistance. In fact, all these features are common symptoms of tuberculosis and possibly manifestation of these features that compels the patient to seek the healthcare facility. Owing to generalised and non-specific nature of these features, none of the previous studies reviewed by us found a significant association of these features with rifampicin resistance.

In the present study the proportion of patient with DM was higher in rifampicin resistant group than rifampicin sensitive group, but was not found to be significant. In study by Saurabh Mehta, Elaine Ann Yu (2015) ${ }^{26}$ states that the increased risk of rifampin resistance in patients with diabetes. Another study by Qianqian Liu, Wenzhang Li $(2016)^{27}$ also shows DM was an independent risk factor for MDR-TB, especially for primary MDR-TB.

In their study, Velayati et al found an association between previous or family history of tuberculosis and rifampicin resistance with $33.6 \%$ patients having either a previous or family history of TB. However, the present study was restricted to only newly diagnosed cases of tuberculosis without a previous 69 history of tuberculosis. Family history of tuberculosis was reported in $13.3 \%$ in Rifampicin sensitive group, but there was increased proportion of family history that is $40 \%$ in Rifampicin-resistant group, but it did not show a significant association with rifampicin resistance $(p=0.360)$.

The fact that history of family contact was a potential risk for rifampicin resistance in present study, it must be possible that source of this drug resistance could be in contact with a person having a history of incomplete treatment of tuberculosis resulting in drug resistance.

The present study had a high prevalence of smokers and alcohol users (66.7\%). There were $26.7 \%$ tobacco users too. A high susceptibility of lung infection is reported in smokers. In several studies, it has been shown to be associated with drug resistance. In fact, smoking affects the clinical manifestation and is a contributory factor in diagnostic delays which eventually might be responsible for emergence of drug resistance. However, the present study failed to establish any such relationship. One of the reasons for this could be a high prevalence of smokers, which overshadowed its clinical significance in view of fewer number of rifampicin resistant cases.

The present study did not find a significant association of different clinical signs such as pallor, icterus, clubbing and oedema with drug resistance. In fact except for pallor which affected $25 \%$ of patients, none of the other signs were positive in a clinically significant proportion of patients to be 
of clinical value for finding out an association with rifampicin resistance.

Among different haemodynamic parameters, the present study found a significant association of low $(<20 / \mathrm{min})$ or high $(>30 / \mathrm{min})$ respiratory rate with rifampicin resistance. On evaluating the literature, we did not come across any study reporting such as association of rifampicin resistance with respiratory rate. Thus, this finding seems to be an incidental finding which requires further exploration.

Majority of cases had unilateral disease $(81.7 \%)$. There were $11(18.3 \%)$ cases having bilateral disease. Though proportion of those with bilateral disease was higher in rifampicin resistant $(40 \%)$ as compared to rifampicin sensitive group $(16.4 \%)$, yet this difference was not significant statistically $(\mathrm{p}=0.181)$.

With respect to chest $\mathrm{x}$-ray finding, cavity and destroyed lung were the findings that comprised only $12.7 \%$ and $9.1 \%$ of rifampicin sensitive group as compared to $40 \%$ each of rifampicin resistant group, while infiltration and infiltration with fibrosis comprised of $41.8 \%$ and $34.5 \%$ of Rifampicin sensitive group as compared to $0 \%$ of Rifampicin-resistant group. Statistically, this difference was not significant ( $\mathrm{p}=0.168)$.

Interestingly, the present study showed simultaneous presentation of GI abnormalities to be significantly but negatively associated with rifampicin resistance. No such relationship between GI abnormalities and rifampicin sensitivity pattern has been reported in previous studies and thus this finding could be set aside and needs further validation.

The present study also showed that absence of associated systemic abnormalities might be significantly associated with risk of rifampicin resistance. ${ }^{28}$ This is another issue that requires further exploration and could be attributable to some confounding factor. As such evaluation of systemic abnormalities requires a specific diagnostic workup and the assessments in present study were based on clinical manifestations and could rule out presence of any unidentified systemic illness. On the other hand, these findings indicate that absence of any associated systemic illness might be responsible for longer diagnostic delays, which might have contributed to drug resistance in these patients.

These observations are of concern. More so given the fact that the rifampicin resistance rates in the present study and other contemporary studies from different parts of India indicate a high rifampicin resistance rate, thus indicating the need to address this problem. To tackle this problem, it is recommended that drug resistance evaluation should be made mandatory part of the tuberculosis control programme and appropriate customised management strategies in view of the drug resistance pattern of individual patient should be made. Moreover, it should be also ensured that all the patients under tuberculosis control programme should be motivated to complete the treatment until complete resolution of tuberculosis, so that source of drug resistance might be checked. Further studies to investigate the rifampicin resistance rate in particular and drug resistance in general must be carried out on a larger sample size in order to assign risk to different possible demographic and clinical variables to identify the source/ risk of rifampicin resistance even in newly diagnosed tuberculosis cases.

\section{CONCLUSION}

One of the concerning issues was that there were no definitive clinical or routine investigations connected with rifampicin resistance, thus showing that passage of resistant strain is quite prevalent in society. To tackle this problem, it is recommended that drug resistance evaluation should be made mandatory part of the tuberculosis control programme and appropriate customised management strategies in view of the drug resistance pattern of individual patient should be made.

\section{REFERENCES}

[1] World Health Organization. Global tuberculosis report 2016. World Health Organization, Geneva, Switzerland, 2016. http://apps.who.int/iris/bitstream/last accessed on 17th April, 2017.

[2] Adane K, Ameni G, Bekele S, et al. Prevalence and drug resistance profile of Mycobacterium tuberculosis isolated from pulmonary tuberculosis patients attending two public hospitals in East Gojjam zone, northwest Ethiopia. BMC Public Health 2015;15:572.

[3] Mukherjee P, Karmakar PR, Basu R, et al. Sociodemographic and clinical profile of multi drug resistant tuberculosis patients: a study at drug resistant tuberculosis centers of Kolkata. IOSR Journal of Dental and Medical Sciences (IOSR-JDMS) 2015;14(8):52-8.

[4] Sahebi L, Ansarin K, Mohajeri P, et al. Patterns of drug resistance among tuberculosis patients in west and Northwestern Iran. The Open Respiratory Medicine Journal 2016;10:29-35.

[5] Lukoye D, Adatu F, Musisi K, et al. Anti-tuberculosis drug resistance among new and previously treated sputum smear-positive tuberculosis patients in Uganda: results of the first national survey. PLoS One 2013;8(8):e70763.

[6] World Health Organization: WHO Report on Global Tuberculosis Control: epidemiology, strategy, financing. Geneva: WHO, 2011.

[7] Kaur R, Jindal N, Arora S, et al. Epidemiology of rifampicin resistant tuberculosis and common mutations in rpob gene of mycobacterium tuberculosis: a retrospective study from six districts 84 of Punjab, India Using Xpert MTB/RIF Assay. Journal of Laboratory Physicians 2016;8(2):96-100.

[8] Guled AY, Elmi AH, Abdi BM, et al. Prevalence of rifampicin resistance and associated risk factors among suspected multidrug resistant tuberculosis cases in TB centers Mogadishu-Somalia: descriptive study. Open Journal of Respiratory Diseases 2016;6:15-24.

[9] Das D, Satapathy P, Murmu B. First line Anti-TB drug resistance in an urban area of Odisha, India. Journal of Clinical and Diagnostic Research JCDR 2016;10(11):DC04-DC06.

[10] Government of India. TB India-2013. Revised National TB Control Programme, Annual Status Report. Central TB Division, Directorate General of Health Services, Ministry of Health and Family Welfare, Government of India. 2013. 
[11] Telenti A, Imboden P, Marchesi F, et al. Detection of rifampicin-resistance mutations in Mycobacterium tuberculosis. Lancet 1993;341(8846):647-50.

[12] Drlica K, Zhao X. DNA gyrase, topoisomerase IV and the 4-quinolones. Microbiol Mol Biol Rev 1997;61(3):377-92.

[13] Cambau E, Sougakoff W, Besson M, et al. Selection of a gyrA mutant of Mycobacterium tuberculosis resistant to fluoroquinolones during treatment with ofloxacin. J Infect Dis 1994;170(2):479-83.

[14] Hirano K, Takahashi M, Kazumi Y, et al. Mutation in pncA is a major mechanism of pyrazinamide resistance in Mycobacterium tuberculosis. Tuber Lung Dis 1997;78(2):117-22.

[15] Heym B, Saint-Joanis B, Cole ST. The molecular basis of isoniazid resistance in Mycobacterium tuberculosis. Tuber Lung Dis 1999;79(4):267-71.

[16] Lemaitre N, Sougakoff W, Truffot-Pernot C, et al. Characterization of new mutations in pyrazinamideresistant strains of Mycobacterium 81 tuberculosis and identification of conserved regions important for the catalytic activity of the pyrazinamidase PncA. Antimicrob Agents Chemother 1999;43(7):1761-3.

[17] David HL. Probability distribution of drug-resistant mutants in unselected populations of Mycobacterium tuberculosis. Appl Microbiol 1970;20(5):810-4.

[18] Schrag SJ, Perrot V, Levin BR. Adaptation to the fitness costs of antibiotic resistance in Escherichia coli. Proc Biol Sci 1997;264(1386):1287-91.

[19] Vennesland K, Ebert RH, Bloch RG. The demonstration of naturally occurring streptomycin resistant variants in the human strain of tubercule bacillus H-37RV. Science 1947;106(2759):476-7.

[20] Mitchison D. The segregation of streptomycinresistant variants of Mycobacterium tuberculosis into groups with characteristic levels of resistance. J Gen Microbiol 1951;5(3):596-604.
[21] Moitra S, Sen S, Das P, et al. Clinico-pathological profile, radiological presentation and drug susceptibility pattern of new smear positive (category I) pulmonary tuberculosis: a single centre experience in Delhi, India. Int J Res Med Sci 2014;2(3):1121-6.

[22] Agwan V, Kansal R, Madan M, et al. Primary multi drug resistance in new pulmonary tuberculosis patients in Western Uttar Pradesh, India. Int J Curr Microbiol App Sci 2015;4(8):656-63.

[23] Coovadia YM, Mahomed S, Pillay M, et al. Rifampicin mono-resistance in Mycobacterium tuberculosis in KwaZulu-Natal, South Africa: a significant phenomenon in a high prevalence TB-HIV region. PLoS One 2013;8(11):e77712.

[24] Mulu W, Abera B, Yimer M, et al. Rifampicin-resistance pattern of Mycobacterium tuberculosis and associated factors among presumptive tuberculosis patients referred to Debre Markos Referral Hospital, Ethiopia: a cross-sectional study. BMC Research Notes 2017;10: p. 8.

[25] Rasaki SO, AJibola AA, Musa SA, et al. Rifampicin resistant tuberculosis in a secondary health institution in Nigeria, West Africa. J Infect Dis Ther 2014;2: p. 139.

[26] Sobhy KA, Elawady S, Latef SA, et al. Patterns of drug resistance in cases of smear positive pulmonary tuberculosis in Giza and Cairo governorates. Egyptian Journal of Chest Diseases and Tuberculosis 2012;61(4):343-8.

[27] Zhou J, Dong Y, Zhao X, et al. Selection of antibioticresistant bacterial mutants: allelic diversity among fluoroquinolone-resistant mutations. J Infect Dis 2000;182(2):517-25.

[28] Seyoum B, Demissie M, Worku A, et al. Prevalence and drug resistance patterns of mycobacterium tuberculosis among new smear positive pulmonary tuberculosis patients in Eastern Ethiopia. Article ID 753492, Tub Res Treatment 2014;2014: p. 7. 